\title{
A Sociolinguistic Analysis of Childhood Narratives and the Construction of Gender Identity: A Sociocultural Perspective
}

\author{
Maha H. Alsoraihi ${ }^{1 \& 2}$ \\ ${ }^{1}$ Associate Professor of Applied Linguistics, Princess Nourah Bint Abdulrahman University, Riyadh, Saudi \\ Arabia \\ ${ }^{2}$ A Fulbright Visiting Scholar at University of Massachusetts of Amherst, USA \\ Correspondence: Maha H. Alsoraihi, Associate Professor of Applied Linguistics, Princess Nourah Bint \\ Abdulrahman University, Riyadh, Saudi Arabia. E-mail: mhalsoraihy@pnu.edu.sa
}

Received: November 23, 2019 Accepted: December 20, 2019 Online Published: January 13, 2020

doi:10.5539/ijel.v10n1p402 URL: https://doi.org/10.5539/ijel.v10n1p402

\begin{abstract}
This paper recognizes various concepts about gender identity in early childhood narratives by analyzing memories and stories expressed by men and women participating in this study. Such analyses assert the fact that cultural norms' influence on gender identity is a very complex process. Linguistic ethnography (LE) researchers have always considered language as a starting point that leads to the study of the interactions between cultural, social norms, and language. This paper is placing a noticeable emphasis on detailed analyses of recorded data of interactions as primary source for displaying and constructing gender identities via social norms differences or similarities. This study emphasizes the effect of cultural differences and how they are placed at the center of other social processes involving gender identities and cultural outcome through daily interactions. Knowledge of the concept of social reality across different fields will eventually lead to key answers of questions about how this reality is constructed, reproduced, and manifested in various social, historical, political, and socio-economic settings. This paper manifests the definition of LE which is a field that is recognized by combining both ethnography and linguistic characteristics, where ethnography lies within the researcher's attempt to analyze communicative practices within the social norms of a particular community. Through participants' voices, events and views, their gender identity is perceived and constructed.
\end{abstract}

Keywords: gender identity, childhood, narratives, cultural norms, stereotypes, sociolinguistics, analysis, linguistic ethnography, gender inequality

\section{Introduction}

During the past decades, researchers have paid attention to the increasing conditions and contradictions attributed to the socio-economic, cultural and linguistic changes. As a result of such changes, there has been an ideological shift from defining languages as specific entities tied to specific communities towards new discourses in which languages are perceived as essential skills in the globalized industrial market (Heller, 2010; Duchene \& Heller, 2012; Codo \& Perez-Milans, 2014).

This paper aims at providing a review of the concept of gender identity and analyzing the contributing social factors that lead to gender identity construction and development by analyzing some childhood narratives expressed by men and women participating in this study. The focus of this study is to display the interplay of various factors such child/parental characteristics, environmental/cultural circumstances, among others. Many studies focused on the effect of various biological and psychological factors on gender identity construction, but few studies discussed the complex interaction between such factors, among others.

The term identity came from a Latin word "identitas", which means the same. Kroger (2007) refers to the idea that every person might have a number of identities such as ethnic identity, a religious identity, or a national identity. The most crucial identity is, however, the gender identity. The term refers to the mental image that someone has to reflect the concept of the "sameness" with others. Gender identity refers to the extent to which one identifies him/herself being like others of the same gender. Being a male or a female is largely determined by how a person views him/herself to be like others of the same gender.

This paper also focuses on the term "gender roles", which includes the attitudes, behaviors, and the personality traits within Saudi society in a specified historical period: late 1970s and early 1980s. The dual concept of gender identity and gender role (GI/GR) was introduced by Money (1994). He believed that gender identity to be 
the private manifestation of gender role, and gender role is the public manifestation of gender identity.

Cognitive developmental researchers focusing on gender identity development have focused on the role of cognitive factors in young children (Ruble et al., 2006). They found that gender learning begins early and goes through various phases (Kohlberg, 1966). According to Serbin et al. (2001) and Zosuls et al. (2009), most children develop the ability to recognize their gender and others' gender between 18 and 24 months. This is mostly due to gender stereotype preferences such as toys, where cars for example are assigned to boys and dolls for girls. Moreover, other behavior preferences have been noticed by Ruble and Martin (1988) that boys prefer rough activities where girls play cooperatively. Lobel et al. (2000) recorded a noticeable increase in the preference for same-sex-playmates.

Our concept of who we are and how we fit into the world involves basic norms which eventually shape our behavior and attitudes. Accordingly, women may find themselves judged according to the existing cultural norms which deeply affect their lives and their choices. Generally speaking, we must admit that certain cultural norms can have a taken-granted status which can affect our behavior in ways that can be unquestioned. Philosophy, as a discipline, is considered the right starting point for further explanations concerning gender behavior. It provides various answers for questions related to moral, cultural, and other social norms.

In fact, any arguments about gender identity must be deeply bound within broader sociocultural norms of race, class, religion, and other social factors. Identities are built upon one's belief about the world; one's gender, race, religion, etc. Therefore, such issues are the main concerns in the disciplines of Philosophy, Gender, and Culture. It must be mentioned that as our own self identities involve a large picture of the world, they also include a recognition of other people and our relations to them. Another important point to mention is that, it is also crucial that one should be open to be viewed by others in a way that does not match with one's own self-conception.

\subsection{Approach of the Study}

This paper adopts the linguistic ethnography approach which has been influenced by the works in the field of interactional sociolinguistics (Gumperz, 1982) and micro-ethnography (Goffman, 1967; Erickson, 1992). This analytic approach involves a focus on people's routines and specific patterns of language usage which in turn entails fine tools for data collection and analysis of audio recordings with elaborated transcriptions of social practices. Consequently, this method helps the researcher to keep a close look at the linguistic and textual data, leading him/her to be involved in every single moment of the recorded data whereby participants can construct frames on their gender identities. This approach requires the researcher's commitment to examine recorded data thoroughly as meaning making and social contexts are interactionally constructed.

The study of language and gender identity via examining issues related to linguistic ethnography has received an increasing attention during the past decades. Researchers who approached linguistic ethnography in relation to language, culture, and community, found out the issues relevant to the concepts of instability and predictability in nowadays settings. Linguistic ethnography can be defined as "a particular configuration of interests within the broader field of socio- and applied linguistics (which include) a theoretical and methodological development orienting towards particular, established traditions but defining itself in the new intellectual climate of poststructuralism and late modernity" (Creese, 2008, p. 229).

It has to be mentioned that Linguistic Ethnography has come into existence under the impact of various fields, including philosophy and language (Austin, 1962; Searle, 1969), Linguistic Anthropology (Hymes, 1968, 1974; Gumperz \& Hymes, 1972; Irvine \& Gal, 2000), Sociolinguistics (Labov, 1972; Gumperz, 1982; Bernstein, 1996); Sociology (Goffman, 1967, 1972, 1981); communication studies and social theory (Hanks, 1996; Bourdiecu, 1972, 1982, 1991).

\subsection{Review of Literature}

Commonly, the concept of gender is either misused or misunderstood. Gender does not only refer to sex and sexuality. Gender can be defined as a social entity that "defines particular acts of performances that are understood to be appropriate to one sex" (Bohan, 1997, p. 13). On the other hand, sex can be defined as referring to "anatomical or chromosomal categories" (Walker \& Cook, 1998, p. 255). Researchers often used the word gender interchangeably for sex (Haig, 2004). Thus, the word gender has been surrounded with a considerable account of confusion. Pogrebin (1980) believed that there is an observable link between gender roles and sexuality in gender research. Most studies assume that in early childhood, gender roles can be determined by the parents and the environments around children (Cahill \& Adams, 1997; Pogrebin, 1980, Hamilton \& Flood, 2008; Willis, 2012).

Gender identity has been investigated by cognitive developmental psychologists for the past few decades. They mainly focused on the cognitive factors of gender identity (Fagot \& Leinbach, 1985; Kohlberg, 1985; Kohlberg, 1966; Ruble \& Martin, 1998). For example, Kohlberg (1966, p. 88) gave a definition of gender identity as the 
“cognitive self-categorization as boy or girl”. Similarly, Fagot and Leinbach (1985, p. 685) considered gender identity to be "the concept of the self as male or female". Recently, studies give more attention to the feelings of contempt with one's gender (affective components) (Egan \& Perry, 2001). Tobin et al. (2010) adopted a model of five dimensions, subdivided into knowledge of a gender category, gender centrality, gender contentedness felt gender conformity, and felt gender typicality, to conceptualize gender identity.

Furthermore, Egan and Perry (2001) discussed various indications for gender differences at the end of childhood as boys develop a stronger gender identity than girls, showing to be more content with their gender. Gender identity is largely determined by gender role behaviors most children in their early childhood. However, in adolescence, gender intensification takes place as Hill and Lynch (1983) asserted. McHale et al. (2009) discussed the time youth spend in gendered social contexts on the development of their gendered interests and personal qualities. For the majority of youth, gender identity seems to be fairly fixed from early childhood (Diamond \& Butterworth, 2008).

Much of the current research on gender and language has attempted to explain gender differences. Chodorow (1978) hypothesized that, as a result of being parented primarily by a woman, men and women develop different gender identities. Through their early relationship with their mother, women develop a sense of self that is continuous with others. Men, on the other hand, develop a sense of self based on denial of this relationship. Thus, the female gender identity is based on a basic sense of connectedness, whereas the male gender identity is grounded in the belief in a separate self.

Research results in the area of language and gender have confirmed the existence of clearly defined stereotypes for men and women as well as a high consensuality with respect to sex role perceptions. For example, women are generally perceived as less competent, less logical, and less objective than men, whereas men are perceived as lacking interpersonal sensitivity, warmth, and expressiveness compared to women (Ashmore, 1981; Broverman et al., 1972).

No doubt that recalling past events serves important social and linguistic functions (Middleton \& Edwards, 1990; Nelson, 1993). There are two main branches of studies on identity (Ford, 2006): the constructivists on one hand, and post-structuralists on the other. As for the first, identity, identity is constructed to the process of constructing a sense of self. This self is a reflexive project, as in (Gidden, 1991) terms: "we are not what we are but we make of ourselves a narrative process of self-making" (p. 75).

The post-structuralist approach distances itself from the philosophical position that supports the idea of unique and coherent core of the individual (Butler, 1990). This approach adopts an account of identity as a function of these discourses that frame the development of a sense of identity. These discourses are language practices which are ways of speaking about topics that "limit the sayable and unsayable" (Barker \& Galasinki, 2001).

Anthropological studies on cultural perspectives have been recently shifted from generalizing approaches to voice narrative productions, related to historical events and personal individuals' needs and interests. This study assumes that such early childhood narratives will shed lights on the complex relationship between personal narratives and socio-historical contexts.

According to the narratological approach, actions were seen as functions (Bal, 1985, p. 26). In other words, it is through participants' voices, events and views, their gender identity is perceived and constructed. Within the narrative pattern, it is found that several classes or categories in which narratives of events can be perceived as patterns of behaviors and attitudes to the construction of gender identity. This paper examines the linguistic communicative conventions through which participants identify via childhood narratives their social actions which consequently construct their gender identity. These conventions involve linguistic aspects such as language choice, lexical choice, coherence, cohesion, etc. This analytical activity is an example of the conversation analysis carried by Sacks, Schegloff and Jefferson (1974). This paper analyzes each recorded and transcribed event as part of the social practices that are narrated by the participants themselves.

This paper focuses on gender as a very important social variable that has an impact on many aspects of behavior and self-concept (Lips, 2001; Ruble \& Martin, 1998). Gender stereotypes are very observable features in our social practices. They have been pictured as powerful predictors of people's behaviors, attitudes and expectations about other behaviors (Lip, 2001). Many gender studies have concluded that individuals tend to associate males with qualities such as unemotional, independent and courageous, whereas females are associated with qualities such as emotional, weak, and socially oriented (Allen, 1995; Martin, 1987; Williams \& Bennett, 1975).

Studies in early childhood gender identity have emerged from various fields of study such as Psychology, Sociology, and Education. Childhood literature shows that children become able to be aware of gendered behaviors between ages of 2-3 (Ebbeck, 1988). Then, from ages 4-5, researchers found that children begin to segregate themselves based on their gender (Creaser \& Dau, 1996). Their understanding of gender can be 
developed into either femininity or masculinity through their interactions with others, social norms, and the world surrounding them (Blaise, 2009; MacNaughton, 1998). Gender expectations can be an action of struggle by children to process (Davies, 1989; Walkerdine, 1990). This struggle can be escalated when children are rewarded or punished according to their gender behaviors (Ewing \& Taylor, 2009).

Studies also show that gender expectations can affect children's understanding of their gender identity through various environmental sources such as toys, books, activities, clothes, etc. Cultures can have direct impacts on children preferences for toys that are "designed, packaged, and marketed to correspond with their masculine or feminine identities" (Kahlenberg \& Hein, 2010, p. 830). Further, social norms and expectations are also linked to this approach (Lindstrand, Insulander, \& Selander, 2016; Robinson, Smith, \& Davies, 2017).

Moreover, according to Thompson (1975), children are able to identify their own sex, and can recognize that some objects and activities are associated with each sex. Further, Best et al. (1977) found that children grasp certain stereotypes by the age of 8 and up as $75 \%$ of 8 years old children can demonstrate knowledge of sextyped traits. Gender identity is completely acquired by about age 7 (Kohlberg, 1966). Concerning linguistic performance, Edelsky's (1977) assumes that American first graders have developed enough knowledge of how men and women speak.

Consequently, it is noticeable that a considerable number of gender studies have asserted that linguistic gender differences are mostly attributed to socially conditioned factors. In other words, these linguistic gender differences are learned and not attributed to biological factors. This study believes so and assumes that the participants' narration about memories and events of their childhood will reflect and demonstrate some linguistic differences as well as some different cultural preferences which can be attributed to a number of socially conditioned factors and not to biological ones. In other words,

"The gender differences referred to in language, is a kind of language phenomenon in the display of society, culture customs, and other considerations of language users. It has a rich cultural background, historical connotation and profound social reality, folk psychology, the social and cultural value orientation" (Dong, 2013, p. 93).

Thus, according to Dong (2013), linguistic gender differences depend on the society and its cultural norms and regulations. Accordingly, this study assumes that analyses of linguistic gender differences that come to surface as participants of this study narrate their childhood memories will be reflected on the construction of their gender identity.

In fact, identity is never independent from social meanings. Instead, by connecting oneself with other variable identity positions, one's identity is created and constructed (Bucholtz \& Hall, 2005, p. 598). Gender is identified linguistically through the citational reiterations of acts of performance which index ideological categories (Butler, 1999, 2011). The linguistic features manifested in such interactions do not show direct social meanings. On the contrary, they indirectly index certain social categories within social discourses (Ochs, 1992). These social meanings are associated with linguistic features from an indexical field of multiple social meanings which can create an individual's identity (Eckert, 2008).

This study focuses on the linguistic gender differences and the cultural stereotypes for each gender found in the participants' narration of childhood events. It must be acknowledged that childhood is a phase where certain restrictions would be imposed on individuals by their parents, social norms, and gendered expectations. These restrictions would definitely have a tremendous impact on the individuals' childhood and their future life in general.

\section{Methodology \& Data Collection}

\subsection{Subjects of the Study}

The subjects of this study (Saudi-educated-middle class) are divided into two groups according to their gender (15 men \& 15 women) where age (45-50) and gender are controlled variables. This means they were born between 1970s and 1975s, and their childhood was at the late of the 1970s and early of 1980s. The researcher asked each person individually to narrate some unforgettable childhood memories that affect him/her either positively or negatively and relate to the issue of gender identity. This narration is audio recorded (upon the participants' assent) for the sake of transcription, translation (if needed) and analysis. This process is a kind of informal interview where the participant is doing much of the talking freely without interruptions or further questions. As Fetterman, (1989, p. 50) points out that "ethnographers use interviews to help classify and organize an individual's perception of reality". This kind of interviews are less formal as Michael Agar (1980, p. 90) wrote, in an informal interview "everything is negotiable. The Participants can criticize a question, correct it, point out that it is sensitive, or answer in any way they want to". The social fieldwork is an attempt to understand how men and women in Saudi Arabia were affected by the social norms and cultural practices at the time of 
1970s and 1980s of their childhood in shaping and constructing their gender identity.

This paper refers to the grounded theory where the analytic process moves from bottom up, from private observations to broad generalizations. This method from data to theory is called "grounded theory" (Glaser \& Strauss, 1967, p. 1) Thus, interviewing and recording individuals' narrations produce lots of fieldnotes which later need to be coded and analyzed. This method fits with Fetterman's analysis (1997): "ethnographers look for patterns of thoughts and behaviors. Patterns are a form of ethnographic reliability" (p. 96). As for feminist poststructuralism, certain studies are the focus of this paper such as (Lather, 2001; St. Pierre, 2000; De Andrade, 2000; Davies, 1999; Weedon, 1998). For identity research, it is worthy to mention the following studies as main references: (Bloome, Carter, Christian, Otto, \& Shuart-Faris, 2005; Gee, 2001; Bhabha, 1994; Hall, 1990).

This paper addresses the tradition status of Saudi men and women in one of the third world countries at that time of late 1970s and early 1980s. It focuses on the past and current changes on both social and economic levels which have impacts on shaping their gender identity. Consequently, the need to examine how children engage to construct their gender identity from their own perspective is essentially crucial and beneficial. It is through this technique; one can be able to examine how gender as a social variable matters to the lives of children in particular contexts and how they construct their gender identity or challenge dominant gender practices. This shows the need to explore the complexity of gender relations and identity constructions. It was fundamental for the researcher to investigate the relation between social practices and the constructing of gender identities.

It is worthy to refer to the social and economic status of Saudi Arabia at that time where participants of this study narrated their childhood memories, approximately by the time of late 1970s and early 1980s.

\subsection{Research Questions:}

1) What are the differences in the use of some linguistic features found in the narratives of childhood memory contexts by Saudi men and women?

2) How do such linguistic features affect the construction of their gender identity?

3) To what extent that one's culture and values have impacts on the use of language and constructing one's gender identity?

4) Which gender can recall childhood memories in detail using elaborated and different linguistic features?

5) Which topics are recalled by both genders? How do such topics have an impact on creating their gender identity?

\section{Data Analysis \& Discussion}

Data has been collected from informal interviews where participants narrated some unforgettable events of their childhood which seem to be connected with constructing their gender identities. Such narratives have been transcribed, coded, and analyzed. The narrative properties were measured according to: (1) narrative length and (2) narrative informativeness. The narrative length is measured by the number of words in the recorded even and the number of the subject-predicate clause. The narrative informativeness is specifically related to how descriptive and informative the narrations were. This is measured by the number of descriptors used. These units were mainly adjectives and adverbs used in the narratives (Fivush, 1991a).

Gender is a sociable variable that influences many aspects of behavior and self-recognition (Lips, 2001; Ruble \& Martin, 1998). However, to the researcher's knowledge, there is few or no one has explored whether the gender of the person affects the sort of narratives about childhood memories and events. Gender stereotypes represent unique aspects of social experiences. They have manifested powerful predictions of individuals' perceptions and predictions of attitudes and beliefs (Lips, 2001).

The purpose of this study is to explore to what extent men's and women's narratives are different/similar, and how such narratives influence their gender identity construction. Findings of this study are discussed and presented statistically using both quantitative and qualitative methods. It is assumed that such results will add up to those findings related to gender studies in general and shed some light on both Saudi culture and social structure.

Because of the little research that has been tackled in this field, some self-narrative properties are investigated and analyzed (Peterson \& Roberts, 2003). These include five categories:

1) Narrative Length. This was measured by the number of words in the narration and the number of clauses of subject-predicates (Peterson, 1994; Buckner \& Fivush, 1998; Leichman et al., 2000).

2) Narrative Elaboration. This is measured by exploring how informative the narration was. This is assessed by counting the unique and new pieces of information. For example, adjectives and adverbs were counted as sources of vividness of information. The total words that represent new information were presented in tables for 
more clarification. This is shown by the following subdivisions: person, location and activity (Buckner \& Fivush, 1998; Peterson, 1994; Jesso \& McCabe, 1999).

3) Cohesion. How sentences are well-structured and connected together. This is measured by counting the linking connectives the narration has (Bennett \& Kastor, 1986; Peterson \& McCabe, 1998).

4) Coherence. This is measured by counting the linguistically links that demonstrate how the events of the narration are related either temporally or conditionally (Buckmen \& Fivush, 1998).

5) Context. (Time \& Place). This is measured by counting the number of links that direct the listener to where and when those childhood events took place. In other words, how the narrators embedded the narrated events into an appropriate context (Fivush, 1998; Peterson, 1994; Peterson et al., 1999).

It has to be mentioned that those five categories have been scored in the same way as have been used in other studies and research mentioned earlier. Moreover, emotion words as well as descriptors of these emotions have been counted. These emotional words may present positive or negative emotions such as happy and upset, respectively. Another noticeable kind of emotion is denial. This makes the measurement of explicit emotions up to three categories.

As for measurement, each of the categories mentioned earlier has been scored separately. This is because some of the categories have some kind of overlap with other categories. Therefore, they are not all somehow independent. As for the process, each narration was independently measured. For categories which involve multiple measures, a MANOVA (multivariate analysis of variance) was applied and calculated. As for the category of cohesion, ANOVA method was applied and calculated. Narratives of the female participants were more cohesive than the narratives of the male participants, $\mathrm{M}(1.227)=6.95, p=.009$. This means that the female participants $F$ (25.1) linked more of their narratives with inter clausal connectives than did the male participants, $(\mathrm{M}=19.6)$.

As for coherence, the number of temporal linguistic pieces was analyzed using MANOVA, where the narratives of the male and female participants were different. In other words, female participants $(\mathrm{F}=9.3)$ were different from male participants $(\mathrm{M}=6.8)$ in the number of causal and conditional connectives in their narratives, $\mathrm{M}$ $(1,233)=5.18, p=.024$, but not in the temporal units (see Tables $1 \& 2)$. The differences in the linguistic usage of emotional words among the participants of this study are illustrated in Table 3.

Table 1. Means of self-narrative analyzed categories of both genders

\begin{tabular}{|c|c|c|c|c|c|c|c|}
\hline Participants & $\begin{array}{l}\text { Length clauses/ } \\
\text { Mean SD }\end{array}$ & $\begin{array}{l}\text { Words Mean } \\
\text { SD }\end{array}$ & $\begin{array}{l}\text { Descriptors } \\
\text { Mean SD }\end{array}$ & $\begin{array}{l}\text { Unique Units/ } \\
\text { Mean SD }\end{array}$ & $\begin{array}{l}\text { Person Mean } \\
\text { SD }\end{array}$ & $\begin{array}{l}\text { Location } \\
\text { Mean SD }\end{array}$ & $\begin{array}{l}\text { Object Mean } \\
\text { SD }\end{array}$ \\
\hline \multirow[t]{2}{*}{ Males } & 54.4 & 317.8 & 21.5 & 62.7 & 4.3 & 4.4 & 8.8 \\
\hline & 39.8 & 247.4 & 22.3 & 39.0 & 3.4 & 2.7 & 5.4 \\
\hline \multirow[t]{2}{*}{ Females } & 59.7 & 354.5 & 17.4 & 64.5 & 5.1 & 4.4 & 9.6 \\
\hline & 44.4 & 258.4 & 15.6 & 34.8 & 3.3 & 2.7 & 5.5 \\
\hline
\end{tabular}

Table 2. Means of cohesion, cohesive and other connectives in the narratives of both genders

\begin{tabular}{llllll}
\hline Participants & $\begin{array}{l}\text { Cohesion } \\
\text { Connectives } \\
\text { Mean SD }\end{array}$ & $\begin{array}{l}\text { Coherence } \\
\text { Casual/Cond. }\end{array}$ & $\begin{array}{l}\text { Temporal Context } \\
\text { Mean SD }\end{array}$ & $\begin{array}{l}\text { Time Context } \\
\text { Mean SD }\end{array}$ & $\begin{array}{l}\text { Spatial Context } \\
\text { Mean SD }\end{array}$ \\
\hline Males & 19.6 & 6.8 & 6.3 & 4.6 & 7.0 \\
& 13.5 & 7.7 & 5.4 & 4.6 & 5.5 \\
Females & 25.1 & 9.3 & 6.5 & 4.0 & 6.9 \\
& 21.0 & 8.1 & 5.5 & 4.4 & 5.7 \\
\hline
\end{tabular}

Table 3. Means for the number of positive and negative emotional words

\begin{tabular}{llll}
\hline Participants & Negative emotions & Positive emotions & Denial emotions \\
\hline Males & $2.52(3.40)$ & $0.96(2.01)$ & $0.87(1.89)$ \\
Females & $4.04(4.47)$ & $1.65(2.40)$ & $0.67(1.77)$ \\
\hline
\end{tabular}

Furthermore, the analyses of the recorded data have manifested some of the Saudi social norms and practices at the time of 1980s which have affected gender identity constructions. Most of the topics that the participants of this study recalled from their childhood memories show obvious connections to their gender identity constructions. For example, male participants have talked mostly in their narratives about topics such as clothes, 
colors, music, dancing, and expressing explicit emotions as practices that affect their identity construction. On the other hand, female participants have talked about different topics such as sports, games, toys, socializing, and feeling dependent. Such practices have obviously impacted their gender identities. To give examples of such narratives is when male participants repeatedly talked about incidents where their parents encouraged them to be tough, independent and not showing tears or emotions, informing them "men don't cry". Furthermore, boys were not encouraged to care too much about their appearance and hair styles; colors were very limited to them. For example, pink, red, yellow and other bright colors were told to be for girls only. Toys such as kitchen stuff, make up, and dolls were only for girls. Playing with such toys by the boys would hurt their feelings as people will consider them different from their gender partners. Moreover, dancing and playing musical instruments were not encouraged by families to allow their boys to learn or practice in public. Such practices were associated with girls' behavior only. Table 4 shows that $90 \%$ of the males' narratives focused on this topic as they were not allowed to dance or play musical instruments. According to their narration, these practices affect their gender identity construction.

The same practices have an impact on girls' gender identity construction too. Girls were not encouraged to play soccer; for example. Their choices for sports activities were very limited. Playing with cars, planes, trains were meant to be for boys only according to the female participants' narratives. Developing their personalities to be socialized and independent were not supported by their families' practices. These kinds of attitudes were meant to be for males mostly. Furthermore, girls' future jobs were very limited to be mostly teachers. Being medical doctors, policemen, firemen, pilots, engineers; etc., were not supported by their families or the educational system at that time. The following Table 4 illustrates the topics found in the participants' narratives where each gender focused on the topics that were missing in their daily routines and have a tremendous effect on shaping their gender identity. The percentage shows how such a topic is repeatedly mentioned in the narratives of their childhood memories of each gender.

Table 4. Topics narrated by each gender

\begin{tabular}{|c|c|c|c|c|c|c|}
\hline Participants & Sports & Colors & Toys & Explicit Emotions & Music \& Dancing & Future Jobs \\
\hline Males & $30 \%$ & $95 \%$ & $75 \%$ & $95 \%$ & $90 \%$ & $50 \%$ \\
\hline Females & $95 \%$ & $45 \%$ & $95 \%$ & $40 \%$ & $40 \%$ & $90 \%$ \\
\hline
\end{tabular}

According to Table 4, it seems clear that when the topic of sport is narrated, nearly $30 \%$ of men participated in this study discussed it as an effective factor in constructing their gender identity. This is because it was a social norm for boys to exercise and play different types of sports. On the other hand, female participants discussed this topic in nearly $95 \%$ of the total narratives of the 15 female participants of this study. At that time, female children felt that their choices in exercising different types of sports were limited due to their gender, as their parents have kept telling them constantly which types were suitable for their gender as females. The same goes with other topics mentioned in Table 4 . As for the topic of colors, $95 \%$ of male participants discussed them whenever they narrated childhood events linked to the construction of their gender identity; whereas $45 \%$ of female participants mentioned this topic as their choice of colors was not limited at that time and they don't feel that this topic affects the construction of their gender identity.

Furthermore, narratives of both male and female participants differed linguistically when they refer to their parents' instructions and reactions, rather than when they were talking about their individual experiences relating to their gender identities constructions. Follow up ANOVAs, it seemed that narratives about their parents' involvement were more vivid and descriptive as 69.5 vs. 59.2 for numbers of descriptors and vivid information pieces respectively.

Furthermore, this gender narrative raises also the issue of gender inequality in language usage. Whenever this issue is discussed, then there is always in mind that one gender's language is dominating the language of the other gender. In the case of the Saudi society, men's language (by religion \& culture power) is still dominating. In other words, Saudi men's language, in most families, are getting more priority than the females', especially at those times of 1970s and 1980s which represent the timing of the narratives of this study. For example, parents always say to their daughters a very common stereotype phrase: "don't compare yourself to your brother". Another example of this gender inequality is when one of the female participants said that: "I had to clean the whole house while my brother was having fun, doing nothing". In fact, the cultural dominance of men is the reason for gender language inequality (Tannen, 1990). Thus, culture plays a very important role in enforcing the phenomenon of language gender differences. Therefore, conservative societies are different from open ones in terms of hindering or facilitating language gender differences and inequality. 


\section{Conclusion}

Analyzing the narratives of this study shows that that boys and girls at the times of late 1970s and early 1980s in Saudi Arabia had difficulty in dealing with their childhood. This part was barely mentioned in local studies that focus on gender studies and the sociology of childhood. This results on having only a list of differences between Saudi boys and girls without explaining how such gender differences are constructed and how they are processed and understood. Sociological studies have shown tremendous dedication, particularly to children and their socialization. In such studies, children appear to be merely as receptacle of actions imposed by adults rather than agents by themselves. This study shows such gender differences from the point of views by the participants themselves as recalling childhood events related to their gender identity construction.

There are various factors that can contribute to giving elaborate explanations for gender differences practices in a particular social context. Among them and mostly effective is gender inequality. For Saudi contexts at the time of late 1970s and early 1980s, it was clear that raising their children was obviously affected by this factor of gender inequality. It is worth mentioning that gender inequalities can be traced in various ways such as unequal access to sport activities, resources, education, jobs, daily routines and other practices. These gender inequalities definitely affect the lives and the gender identity construction of children (boys \& girls) according to cultural concepts of femininities and masculinities (Peacock, 2014). In every socially-cultural setting, individuals are socialized to conform to certain rules that affect their construction of gender identity. Studies conducted with individuals from LMICs (low-and-middle income countries) reflect the complexity of gender attitudes that endorse norms of inequality that are thought to be harmful for both boys and girls. The qualitative results suggest that boys and girls in certain cultural contexts endorse gender norms that perpetuate gender inequalities. The quantitative results suggest that gender-based differences may be due to different gender socialization processes. females' and males' narratives seem to be shaped and identified by how families, peers, teachers restrict their freedom. Further, gender attitudes seem to vary according to crucial factors such as ethnicity, age, race, history, and social class. This study reinforces the powerful effects of families and caregivers in shaping the gender attitudes and practices of young children.

\subsection{Recommendations}

What is needed is:

1) Measurement of personal gender attitudes across various settings is variable. There is a need for a better definition of measuring individual gender attitudes.

2) A need for longitudinal studies for a better understanding of the evolving nature of gender attitudes in early childhood and their impact on their lives.

3) A better understanding is needed of the role played by communities and social institutions such as schools, media, and religious communities on forming gender attitudes.

\section{Acknowledgment}

Preparation of this paper was supported by Fulbright Programs for exchanging visiting scholars. Their continuous support is much highly appreciated. Thanks, are also extended to University of Massachusetts of Amherst and the researcher's home university: Princess Nourah University at Riyadh, Saudi Arabia. Thanks also are dedicated to the participants of this study who were very cooperative and friendly in narrating childhood personal stories that have impacts on their gender identity construction. This study is a way of reflecting within to understand something which is greater than the self and connected to a greater cultural context.

"It may be Utopian to believe that language use will ever become "neutral". Human use everything around them - and language is just a thing in that sense - to create differences among themselves" (Wordhaugh, 2010, p. 354)

\section{References}

Agar, M. (1980). The professional stranger. New York: Academic Press.

Allen, B. P. (1995) Gender stereotypes are not accurate: A replication of Martin (1987) using diagnostic vs. selfreport and behavioral criteria. Sex Roles, 32, 583-600. https://doi.org/10.1007/BF01544213

Ashmore, R. D. (1981). Sex Stereotypes and Implicit Personality Theory. In David L. Hamilton (Ed.), Cognitive Processes in Stereotyping and Intergroup Behavior (pp. 36-78). Lawrence Erlbaum Associates.

Bal, M. (1985). Narratology. Toronto/Buffalo/London: University of Toronto Press.

Barker, C., \& Darius, G. (2001). Cultural Studies and Discourse Analysis: A Dialogue on Language and Identity. London: Sage. 
Best, D. L. et al. (1977). The development of sex-trait stereotypes. Child Development, 48, 1375-1384. https://doi.org/10.2307/1128496

Bhabha, H. (1994). The Location of Culture (p.18). Routledge, New York.

Blaise, M. (2009). "What a girl wants, what a girl needs": Responding to sex, gender, and sexuality in the early childhood classroom. Journal of Research in Childhood Education, 23(4), 450-460. https://doi.org/10.1080/02568540909594673

Bloome, D., Carter, S. P., Christian, B. M., Otto, S., \& Shuart, F. (2005). Discourse Analysis and the study of Classroom Language and Literacy Events: A Microethnographic Perspective (p. 244). Lawrence Erlbaum Associates, Mahwah, NJ.

Bohan, J. S. (1997). Regarding Gender. Essentialism, constructionism and feminist psychology. In M. Gergen \& S. N. Davis (Eds.), Toward a New Psychology of Gender: A Reader (pp. 31-47). New York, NY: Routledge.

Bourdieu, P. (1972). Esquisse d' une theorie de la partique. Geneve: Droz. https://doi.org/10.3917/droz.bourd.1972.01

Bourdieu, P. (1982). Ce que parler veut dire. Paris: Fayard.

Broverman, M., Klaiber, E. L., Kobayshi, Y., \& Vogel, W. (1972). Comments on "Roles of activation and inhibition in sex differences in cognitive abilities". Psychological Review, 180-184. https://doi.org/10.1037/h0032280

Brown, P. (1980) How and Why Are Women More Polite: Some Evidence from Mayan Community. In S. McConnell-Ginet, R. Broker \& N. Furman (Eds.), Women and Language in Literature and Society (pp. 111-149). New York: Praeger.

Bucholtz, M., \& Hall, K. (2005). Identity and Interaction: a Sociocultural Linguistic approach. Discourse Studies, 7(4-5), 585-614. https://doi.org/10.1177/1461445605054407

Buckner, J. P., \& Fivush, R. (1988). Gender and self in children's autobiographical narratives. Applied Cognitive Psychology, $12, \quad 407-429 . \quad$ https://doi.org/10.1002/(SICI)1099-0720(199808)12:4<407::AIDACP575>3.0.CO;2-7

Butler, J. (1990). Gender trouble, feminist theory, and psychoanalytic discourse (pp. 324-340).

Cahill, B., \& Adams, E. (1997). An exploratory study of early childhood teachers' attitudes toward gender roles. Sex Roles: A Journal of Research, 36(7-8), 517-529. https://doi.org/10.1007/BF02766688

Chodorow, N. J. (1989). Feminism and psychoanalytic theory. New Haven, CT: Yale University Press.

Coates, J., \& Cameron, D. (Eds.). (1988). Women in their speech communities. New York: Longman.

Codo, E., \& Perez-Milans, M. (2014). Multilingual discursive practices and processes of social change in globalizing institutional spaces: a critical ethnographic perspective. International Journal of Multilingualism, 11(4), 1-8.

Creaser, S., \& Dau, E. (1996). The anti-bias approach in early childhood. NSW, Australia: Harper Educational.

Creese, A. (2008). Linguistic Ethnography. In K. A. King \& N. H. Hornberger (Eds.), Encyclopedia of Language and Education (2th ed., volume 10: Research methods in language and education, pp. 229-241). New York: Springer.

Diamond, L. M., \& Butterworth, M. (2008). Questioning gender and sexual identity: dynamic links over time. Sex Roles, 59, 365-376. https://doi.org/10.1007/s11199-008-9425-3

Dong, J. (2013). Mobility, voice, and symbolic restratification: An ethnography of 'elite migrants' in urban China. Diversities, 14(2).

Duchene, A., \& Heller, M. (eds.) (2012). Language in Late Capitalism: Pride and Profit. New York: Routledge. https://doi.org/10.4324/9780203155868

Ebbeck, M. (1998). Gender in early Childhood revisited. Australian Journal of Early Childhood, 23(1), $29-34$. https://doi.org/10.1177/183693919802300107

Egan, S. K., \& Perry, D. G. (2001). Gender identity: a multidimensional analysis with implications for psychological adjustment. Dev. Psychol., 37, 451-464. https://doi.org/10.1037/0012-1649.37.4.451

Erickson, F. (1992). Ethnographic Microanalysis of Interaction. In M. LeCompte, W. Millroy \& J. Preissle (Eds.), The Handbook of Qualitative Research in Education (pp. 201-225). New York: Academic Press.

Ewing, A. R., \& Taylor, A. R. (2009). The role of child gender and ethnicity in teacher-child relationship quality 
and children's behavioral adjustment in preschool. Early Childhood Research Quarterly, 24(1), 92-105. https://doi.org/10.1016/j.ecresq.2008.09.002

Fagot, B. I., \& Leinbach, M. D. (1985). Gender identity: some thoughts on an old concept. J. Am. Acad. Child Psychiatry, 24, 684-688. https://doi.org/10.1016/S0002-7138(10)60110-0

Fetterman, D. (1997). Empowerment Evaluation: A Response to Patton and Scriven. Evaluation Practice, 18(3), 253-266. https://doi.org/10.1177/109821409701800308

Fivush, R. (1991a). The social construction of personal narratives. Merrill-Palmer Quarterly, 37, 59-81.

Fivush, R. (1991b). Gender and emotion in mother-child conversations about the past. Journal of Narrative and Life History, 1, 325-341. https://doi.org/10.1075/jnlh.1.4.04gen

Fivush, R. (1998). Gendered Narratives: Elaboration, Structure, and emotion in parent-child reminiscing across the preschool years. In C. P. Thompson, D. J. Herrmann, D. Bruce, J. D. Read, D. G. Payne \& M. P. Toglia (Eds.), Autobiographical Memory: Theoretical and Applied Perspectives (pp. 79-103). Mahwah, NJ: Erlbaum. https://doi.org/10.4324/9781315784250-6

Flynn, E. (1991). Politicizing the composing process and women's ways of interacting: A response to A conversation with Mary Belenky. Journal of Advanced Composition, 11, 173-178.

Gee, J. P. (2001). Reading as situated language: A sociocognitive perspective. Journal of Adolescent \& Adult Literacy, 44, 714-725. https://doi.org/10.1598/JAAL.44.8.3

Giddens, A. (1991). Modernity and Self-Identity: Self and Society in the Late Modern Age. Stanford: Stanford University Press.

Goffman, E. (1967). Interactional Ritual Essays on Face-to-face Behavior. New York: Pantheon Books.

Gumperz, J. (1982). Discourse Strategies. Cambridge: Cambridge University Press. https://doi.org/10.1017/CBO9780511611834

Haig, D. (2004). The inexorable rise of gender and the decline of sex: Social change in academic titles, 19452001. Archives of Sexual Behaviour, 33(2), 87-96. https://doi.org/10.1023/B:ASEB.0000014323.56281.0d

Hamilton, C., \& Flood, M. G. (2008). Mapping homophobia in Australia. In S. Robinson (Ed.), Homophobia: An Australian history (pp. 16-38). Sydney, Australia: Federation Press.

Hanks, W. (1996). Language and Communicative Practices. Colorado: Westview Press.

Heller, M. (2010). Linguistic Commodification. Annual Review of Anthropology, 39, 101-114. https://doi.org/10.1146/annurev.anthro.012809.104951

Hymes, D. (1968). The Ethnography of speaking. In J. Fishman (Ed.), Readings in the Sociology of Language (pp. 99-138). Moulton: The Hague. https://doi.org/10.1515/9783110805376.99

Hymes, D. (1974). Foundations in Sociolinguistics: An Ethnographic Approach. Philadelphia: University of Pennsylvania Press.

Irvine, J. T., \& Gal, S. (2000). Language ideology and linguistic differentiation. In P. V. Kroskrity (Ed.), Regimes of language (pp. 35-83). Santa Fe, NM: School of American Research Press.

Kahlenberg, S., \& Hain, M. (2010). Progression on Nickelodeon? Gender-role stereotypes in toy commercials. Sex Roles, 62, 830-847. https://doi.org/10.1007/s11199-009-9653-1

Kroger, J. (2007). Why is identity achievement so exclusive? Identity Int. J. Theory Res., 7, 331-348. https://doi.org/10.1080/15283480701600793

Labov, W. (1972). Sociolinguistic Patterns. Philadelphia, PA: University of Pennsylvania Press.

Lindstrand, F., Insulander, E., \& Selander, S. (2016). Multimodal representations of gender in young children's popular culture. Mediekultur, 6-25. https://doi.org/10.7146/mediekultur.v32i61.22433

Lips, H. M. (2001). Sex and Gender: An Introduction (4th ed.). Mountain View, CA: Mayfield.

Lobel, T. E., Bar-David, E., Gruber, R., Lau, S., \& Bar-Tal, Y. (2000). Gender scheme and social judgments: a developmental study of children from Hong Kong. Sex Roles, 43, 19-42. https://doi.org/10.1023/A:1007035611440

Lynch, J. G. J. (1983). The Role of External Validity of Experiments in Theoretical Research. Journal of Consumer Research, 10(1), 109-111. https://doi.org/10.1086/208949

MacNaughton, G. (1998). Improving our gender equity 'tools': A case for discourse analysis. In N. Yelland (Ed.), Gender in early childhood (pp. 149-174). London, England: Routledge. 
McHale, S. M., Kim, J. Y., Dotterer, A. M., Crouter, A. C., \& Booth, A. (2009). The development of gendered interests and personality qualities from middle childhood through adolescence: a biosocial analysis. Child Dev., 80, 482-495. https://doi.org/10.1111/j.1467-8624.2009.01273.x

Middleton, D., \& Edwards, D. (1990). Collective remembering. London: SAGE.

Money, J. (1994). The concept of gender identity disorder in childhood and adolescence after 39 years. J. Sex Martial Ther., 20, 163-177. https://doi.org/10.1080/00926239408403428

Nelson, K. (1993). The Psychological and Social Origins of Autobiographical Memory. Psychological Science. https://doi.org/10.1111/j.1467-9280.1993.tb00548.x

Ochs, E. (1991). Indexing Gender. In A. Duranit \& C. Goodwin (Eds.), Rethinking Context: Language as an interactive phenomenon (pp. 335-358). Great Britain: Cambridge University Press.

Peacock, D., \& Barker, G. (2014). Working with Men and Boys to Prevent Gender-based Violence: Principles, Lessons Learned, and ways forward. Men and Masculinities, 17, 578-599. https://doi.org/10.1177/1097184X14558240

Pereze-Milans, M. (2014). Mandarin Chinese in London Education: Language Aspirations in a Working-Class Secondary School. Working Papers in Urban Language and Literacies (p. 129), King's College London. https://doi.org/10.1007/s10993-014-9345-8

Peterson, C. (1999). Children's memory for medical emergencies: Two years later. Developmental Psychology, 35, 1493-1506. https://doi.org/10.1037/0012-1649.35.6.1493

Peterson, C., \& McCabe, A. (1994). A social interactionist account of developing decontextualized narrative structure and content. First Language, 12, 299-321. https://doi.org/10.1177/014272379201203606

Peterson, C., \& McCabe, A. (1998). The connective "and" as discourse glue. First Language, 8, 19-28. https://doi.org/10.1177/014272378800802202

Peterson, C., \& Roberts, C. (2003). Like mother, like daughter: Similarities in narrative style. Developmental Psychology, 39, 551-562. https://doi.org/10.1037/0012-1649.39.3.551

Pogrebin, L. C. (1980). Growing up free: raising your child in the 80's. New York, NY: McGraw-Hill.

Robinson, K., Smith, E., \& Davies, C. (2017). Responsibilities, tensions and ways forward: Parents' perspectives on children's sexuality education. Gender and Sexuality in Education and Health, 17(3), 333-347. https://doi.org/10.1080/14681811.2017.1301904

Roen D. H., \& Johnson D. M. (1992). Perceiving the effectiveness of written discourse through gender lenses: The contribution of complimenting. Written Communication, 9, 435-464.

Roulis, E. (1990). The relative effect of gender-linked language effect and a sex role stereotype effect on readers' responses to male and female argumentative-persuasive writing. Unpublished doctoral dissertation, University of Minnesota, Minneapolis.

Rubin D. L., \& Greene K. (1992). Gender-typical style in written language. Research in the Teaching of English, $26,7-40$.

Ruble, D. N., \& Martin, C. L. (1988). Gender development. In W. Damon (Series Ed.) \& N. Eisenberg (Vol. Ed.) Handbook of child psychology: Vol. 3. Social, emotional and personality development (5th ed., pp. 25-104). New York: Wiley.

Sacks, H., Schegloff, E., \& Jerfferson, G. (1974). A Simplest Systematic for the Organization of Turn-taking for Conversation. Language, 50, 696-735. https://doi.org/10.1353/lan.1974.0010

Searle, J. (1969). Speech Acts. Cambridge: Cambridge University Press. https://doi.org/10.1017/CBO9781139173438

Smith. P. (1985). Language, the sexes a society. Oxford, England: Basil Blackwell.

Thorne B., Kramarae, C., \& Henley, N. (1983). Language, gender and society: Opening a second decade of research. In B. Thorne, C. Kramarae \& N. Henley (Eds.), Language, gender and society (pp. 7-24). Cambridge, MA: Newbury House/Harper \& Row.

Tobin, D. D., Menon, M., Spatta, B. C., Hodges, E. V. E., \& Perry, D. G. (2010). The intrapsychic of gender: a mode; of self-social organization. Psychol Rev., 117, 601-622. https://doi.org/10.1037/a0018936

Walker, P. L., \& Cook, D. C. (1998). Gender and sex: Vive la difference. American Journal of Physical Anthropology, 106(1), 255-259. https://doi.org/10.1002/(SICI)1096-8644(199806)106:2<255::AIDAJPA11>3.0.CO;2-\# 
Wardhaugh, R. (2010). An Introduction to Sociolinguistics. Oxford: Blackwell.

West, C., \& Zimmerman, D. H. (1991). Doing gender. In J. Lorber \& S. A. Farrell (Eds.), The social construction of gender (pp. 13-37). Newbury Park, CA: Sage.

Williams, J. E., \& Bennett, S. M. (1975). The definition of sex stereotypes via the adjective check list. Sex Roles, I, 327-337. https://doi.org/10.1007/BF00287224

Willis, P. (2012). Constructions of lesbian, gay, bisexual and queer identities among young people in contemporary Australia. Culture, Health \& Sexuality, 14(10), 1213-1227. https://doi.org/10.1080/13691058.2012.724087

\section{Copyrights}

Copyright for this article is retained by the author, with first publication rights granted to the journal.

This is an open-access article distributed under the terms and conditions of the Creative Commons Attribution license (http://creativecommons.org/licenses/by/4.0/). 